\title{
O PERFIL DO MOTORISTA DE APLICATIVO NO BRASIL
}

\author{
Recebido em 13/04/2021, aprovado em 20/05/2021 \\ 10.30612/mvt.v8i14.14406 \\ Ana Cláudia Bessa'
}

\begin{abstract}
RESUMO: O presente artigo relata dados da pesquisa monográfica para um Trabalho de Conclusão de Curso (TCC) para graduação em Sociologia. O tema da pesquisa foi sobre as representaçôes da atividade por aplicativo para os trabalhadores brasileiros e o recorte parcial para a elaboração do presente artigo se refere aos dados da primeira parte do questionário dedicada à descrição do perfil desses trabalhadores. A investigação para descrição do perfil teve o propósito de contribuir com informaçóes empíricas originais que permitam desenvolvimentos nos estudos sociológicos sobre os trabalhadores que estão exercendo essa nova modalidade de trabalho. O objetivo deste texto é apresentar os resultados quantitativos obtidos sobre o perfil dos trabalhadores e relatar breves análises considerando as características em variáveis como gênero, idade, raça, região, estado civil, entre outras. As respostas permitem observar relaçóes entre a atividade por aplicativo e esses trabalhadores, revelando uma populaçáo composta majoritariamente por indivíduos provedores de suas famílias que atuam em uma atividade cuja lógica flexível é baseada em incertezas e ausência de proteção social.
\end{abstract}

Palavras-chave: Trabalho por aplicativo. Uber. Sociologia do Trabalho. Economia Política.

\section{THE PROFILE OF PLATFORM WORKERS IN BRAZIL}

ABSTRACT: This article reports data from a research at the undergraduate school in Sociology. The profile of Brazilian platform workers is the result of the first part of the survey on that research and contributes to empirical information for sociological related to the subject of platform work. The purpose of this article is to present the quantitative results obtained on the survey and briefly report variables such as gender, age, race, region, marital status, among others in such workers' profile. The results show the platform workers are mainly breadwinners in flexible jobs living with uncertainties and lack of social protection.

Keywords: Platform work. Uber. Sociology of Work. Political Economy.

1 Graduanda em Sociologia pela Universidade Federal Fluminense (UFF). Editora-adjunta da Revista Ensaios (Publicação do corpo discente do Programa de Pós-Graduação em Sociologia - PPGS e das graduaçóes em Ciências Sociais e Sociologia da UFF). Pesquisadora e integrante do grupo de pesquisa certificado no Conselho Nacional de Desenvolvimento Tecnológco (CNPq): Subjetividade, Memória e Violência do Estado, da Universidade Federal Fluminense (UFF). E-mail: anabessa.uff@gmail.com. 


\section{EL PERFIL DE LOS TRABAJADORES DE PLATAFORMA EN BRASIL}

RESUMEN: Este artículo reporta datos de la investigación monográfica para estudios de pregrado en Sociología. El tema de investigación fue sobre las representaciones de la actividad de aplicativos para los trabajadores brasileños y el corte parcial para la elaboración de este artículo se refiere a los datos de la primera parte del cuestionario dedicada a la descripción del perfil de estos trabajadores. La investigación para la descripción del perfil tuvo el propósito de aportar información empírica original que permita desarrollos en los estudios sociológicos sobre los trabajadores que están ejerciendo esta nueva modalidad de trabajo. El propósito de este texto es presentar los resultados cuantitativos obtenidos sobre el perfil de los trabajadores y reportar breves análisis considerando las características en variables como sexo, edad, raza, región, estado civil, entre otras. Las respuestas permiten observar las relaciones entre la actividad y estos trabajadores, revelando una población compuesta principalmente por individuos que mantienen a sus familias que laboran en una actividad cuya lógica flexible se basa en las incertidumbres y la desprotección social.

Palabras Clave: Trabajo de plataforma. Uber. Sociología del Trabajo. Economia Política.

\section{INTRODUÇÃO}

Os dados sobre o perfil do motorista por aplicativo no Brasil, apresentados neste artigo, são parte integrante de uma pesquisa monográfica maior, desenvolvida para elaboração de um Trabalho de Conclusão de Curso (TCC) para graduação em Sociologia. A pesquisa, iniciada em 2019 e concluída em 2020, investigou os motoristas que atuam na atividade por aplicativo e foi composta por três seçôes (BESSA, 2020). Além da primeira seção sobre o perfil dos motoristas por aplicativo que será relatada neste artigo -, a pesquisa teve a segunda seção dedicada às condiçôes da atividade ${ }^{2}$ e a terceira seção sobre a interferência da pandemia ${ }^{3}$ na atividade. Devido ao fato de que a pesquisa ficou bastante robusta, o que originaria um artigo muito extenso, as demais partes serão integrantes de artigos futuros.

A pesquisa seria feita de forma presencial, mas com a pandemia de Covid-194 o planejamento e execuçáo da pesquisa foram adaptados para ser realizado pela Internet de modo a permitir a sua continuidade sem a necessidade de contato pessoal entre pesquisadora e interlocutores/as. A coleta de dados foi feita através de um survey e a transferência do questionário para o ambiente digital promoveu uma mudança importante na característica da pesquisa, pois a mesma seria feita somente em um bairro da cidade de Niterói (RJ). A partir da definição de que a pesquisa seria feita online, foi possível aumentar consideravelmente a sua abrangência de modo a alcançar todo o Brasil.

\footnotetext{
2 A título de informação complementar, a segunda parte da pesquisa explorou as condiçóes da atividade. Os trabalhadores deram informaçóes sobre jornada de trabalho, tempo de permanência na atividade, folgas, renda, os recursos próprios que usam no exercício do trabalho, satisfação, motivação, entre outras questôes (BESSA, 2020).

3 A interferência na pandemia foi explorada na pesquisa na terceira seção das perguntas e revelou questóes importantes sobre os trabalhadores e a atividade frente a este momento social que atingiu de forma impactante o trabalhador brasileiro. No caso dos motoristas, como a atividade é configurada pela necessidade de contato pessoal, as respostas revelaram perdas financeiras e também medo de trabalhar neste contexto (BESSA, 2020).

$4 \quad$ Pandemia é uma epidemia relacionada a uma doença transmissível que se espalha em grandes regióes demográficas (FIOCRUZ, 2020). No Brasil, as restriçôes da pandemia de Covid-19 foram decretadas em Março de 2020 quando a pesquisa estava sendo elaborada.
} 
Para que a pesquisa pudesse atingir sua população alvo, a opção foi pelo uso das redes sociais. Para isso, grupos de motoristas de aplicativo no Facebook foram usados como via de acesso a esses trabalhadores. Os grupos de relacionamento virtual nesta rede social se mostraram ser uma rica fonte de observação e obtenção de dados, pois é um local onde estes trabalhadores se expressam, se relacionam, trocam informaçóes, oferecem serviços e dão depoimentos sobre suas rotinas e questóes de trabalho. A observação não-participativa neste ambiente foi fundamental na elaboração do questionário e na análise das respostas.

Este artigo objetiva evidenciar as relações entre os indivíduos e as práticas da atividade, dentro e fora do trabalho, os componentes materiais e imateriais que permeiam essas relaçóes e como os indivíduos se posicionam dentro da realidade trabalhista no Brasil. Para tanto, serão consideradas as relevantes questôes que se desenvolvem em meio aos debates sobre as transformaçôes a partir do mercado de trabalho informacional, automatização e a chamada gig economy ${ }^{5}$. A investigação sobre a descrição do perfil dos motoristas de aplicativo pretende relacionar os dados obtidos nas respostas ao survey com o contexto socioeconômico brasileiro e teorias sociológicas que contribuam para compreender a complexidade deste mercado de trabalho que se desenvolve sob os impactos de uma situação de crise política, econômica e social. Deste modo, além dos resultados apresentados na primeira parte da pesquisa, este artigo procura contextualizar e trazer conceitos sociológicos que atravessam este fenômeno, tratando de tópicos relacionados à atividade por aplicativo, uberização, flexibilização do trabalho, desemprego e mercado de trabalho no Brasil.

\section{METODOLOGIA}

A pesquisa monográfica que deu origem a este artigo caracterizou-se como uma pesquisa exploratória. A pesquisa exploratória tem o objetivo de explorar um fenômeno ou campo social em busca de novos esclarecimentos para desenvolvimento de novas hipóteses e estudos posteriores (GIL, 2008). É também um tipo de pesquisa mais flexível que permite uma coleta de dados menos convencional como é o caso da pesquisa pela Internet, sem contato presencial entre o/a pesquisador/a e os/as interlocutores/as.

A metodologia quantitativa - adequada às pesquisas exploratórias - foi o caminho escolhido para colher dados e adensar a investigação. A abrangência nacional - a partir da transferência para o ambiente virtual - contribuiu positivamente para a pesquisa. Isso porque o volume maior de dados permite que análises numéricas estatísticas forneçam um bom nível de acerto e maior possibilidade de precisão nas conclusôes. O survey permite - com relativa rapidez - uma investigação da realidade da população pesquisada, possibilitando a quantificação dos dados e confecção de tabelas que geram respostas probabilísticas consistentes. Por outro lado, não capta com clareza as perspectivas pessoais dos/as respondentes ou algum processo de mudança que aconteça no decorrer da aplicaçáo do questionário, exigindo ponderação do/a pesquisador/a no momento do tratamento dos dados e de construção de suas conclusóes, pois há necessidade de enxergar além da leitura simples dos números.

5 O termo gig economy é utilizado para caracterizar a economia da informalidade no mercado de trabalho informacional, onde as relaçóes de trabalho ocasional (no Brasil, chamados de "bicos") passam a ser mediadas pelas plataformas de aplicativo. Um mercado em amplo crescimento dentro e fora do Brasil: "A outra tendência é a plataformização do trabalho. Talvez a modalidade mais conhecida dessa tendência seja a do trabalho informal ("trabajo de changas") por meio de plataformas ("gig labour"), em que trabalhadores (enquadrados como autônomos - "freelancers") realizam atividades de trabalho em troca de pagamento por tarefa para diversos clientes - aos quais somente são acessados por meio de intermediaçáo da empresa plataforma. Trabalhadores que trabalham com Uber, Freelancer, Zolvers e outras plataformas exemplificam essa tendência” (ZUKERFELD, 2020, p. 4, tradução nossa). 
Para isso, é importante integrar análise de dados com os fundamentos teóricos (GIL, 2008). Nesta investigação, a metodologia quantitativa se mostrou adequada por permitir essas variadas análises a partir de uma fonte primária capaz de fornecer uma grande quantidade de dados, ser distribuída pela Internet e por abranger todo o território nacional.

A pesquisa foi desenvolvida em dois estágios que envolveram um questionário pré-teste e o questionário principal da pesquisa. $\mathrm{O}$ uso das redes sociais foi o caminho utilizado para distribuição dos questionários pela Internet, pois o Facebook possui grupos destinados a motoristas de aplicativos onde os questionários foram divulgados entre a população-alvo. O questionário pré-teste foi desenvolvido com o objetivo de saber se as questóes elaboradas atendiam de forma eficaz ao objetivo de coleta de informações e também para experimentar as estratégias de distribuição e divulgação.

Para confecção do questionário foi usada a ferramenta Google Forms ${ }^{6}$ que permite elaborar o questionário e fornece um link de acesso - ou endereço eletrônico - para divulgação. Deste modo, o pré-teste foi distribuído - de forma aleatória nesta fase - em grupos de motoristas de aplicativo. Em virtude do modo de operação dos grupos, era preciso que as postagens fossem aprovadas pelos administradores dos mesmos. A distribuição foi feita em 20 grupos e aceitação ocorreu em seis deles, tendo ficado disponível por sete dias, obtendo apenas 20 respostas. Esta etapa foi fundamental para analisar as possíveis falhas na elaboração e na estratégia de comunicação com o campo de modo a buscar um aumento na eficácia da pesquisa.

Diante dos resultados do pré-teste, após uma observação mais apurada no campo e correçóes na redação do questionário, um novo formulário foi criado. Na segunda etapa, os grupos de motoristas no Facebook foram selecionados seguindo um recorte que usou a empresa Uber $^{7}$ como referência. Esse recorte foi feito através do uso de uma lista - disponibilizada no site da empresa - onde constam as cidades onde a empresa atua em todas as regióes do Brasil ${ }^{8}$. Seguindo os procedimentos do pré-teste, o link do segundo questionário também precisou ser aprovado pelos administradores dos novos grupos selecionados. A distribuição do questionário principal alcançou resultados mais expressivos, obtendo aprovação em 63 grupos de Facebook voltados para motoristas de aplicativo, sendo disponibilizada por 54 dias - de 09 de Abril a 01 de Junho de 2020 - e recebendo 766 respostas. A mudança de estratégia - a partir da experiência do pré-teste - foi fundamental para a melhoria do desempenho da pesquisa e o fato de ter sido realizada pela Internet, permitiu que motoristas de todas as regióes do Brasil fossem alcançados. É importante ressaltar que uma pesquisa presencial - em um tempo limitado como o de uma monografia de conclusão de curso - não teria condiçôes de alcançar tantas respostas em tão pouco tempo como acontece quando a pesquisa é feita em ambiente virtual. Essa alternativa se transformou em um ganho importante para a pesquisa, convertendo em virtude as desvantagens e dificuldades ocasionadas pela pandemia.

O tratamento dos dados quantitativos, a construção dos gráficos e tabelas e as análises estatísticas das respostas foram feitos através da própria ferramenta do Google e também com o uso

\footnotetext{
6 A Ferramenta da empresa Google permite criar formulários que podem ser distribuídos pela Internet e suas respostas contabilizadas automaticamente. Disponível em <https://www.google.com/intl/pt-BR/forms/about/>. Acesso em: 04 jan. 2020. 7 A Uber foi utilizada como referência por ser a empresa de maior projeção no setor. A empresa foi inspiração para o termo "uberização", como caracterização da modalidade de trabalho através de plataformas de aplicativo. Disponível em: <https:// www.uber.com/>. Acesso em: 04 jan. 2020.

$8 \quad$ No momento da pesquisa, constavam 132 cidades na lista que está disponível no site da empresa Uber, Dessas, 97 cidades foram pesquisadas e 31 não entraram na pesquisa. Isso porque nem todas as cidades tinham grupos ativos ou eram grupos com movimento muito fraco e náo forneceram dados suficientes para análise. Ver lista em <https://www.uber.com/pt-BR/blog/ em-quais-cidades-a-uber-esta-no-brasil>. Acesso em: 09 abr. 2020.
} 
do programa PSPP9 . O cruzamento das respostas com dados oficiais foi feito quando possível e necessário. Finalizando, foi feita uma integração entre a interpretação dos resultados - e as questôes abordadas - com as análises sociológicas a partir dos conceitos teóricos relacionados.

\section{A ATIVIDADE POR APLICATIVO}

A modalidade de trabalho por aplicativo se desenvolveu a partir de empresas de tecnologia que criam projetos de modelos de negócio que sejam altamente rentáveis e facilmente replicáveis. Esses modelos de negócio são baseados no uso de tecnologias destinadas a telefones celulares e podem chegar a ter valor de mercado em torno de um bilhão de dólares (TEODORO; D'AFONSECA, 2017). Ou seja, são empresas de grande circulação de capital.

A atividade por aplicativo se caracteriza por uma plataforma digital onde o trabalhador se cadastra para o desempenho de trabalhos informais e remunerados conforme demanda. Por isso, são também conhecidas como atividades on-demand e gig economy. As regras para o cadastro e desempenho da atividade são determinadas e impostas pelas empresas, sem instrumentos públicos de controle e fiscalização. Além disso, são atividades laborais que exigem pouca qualificação para serem desempenhadas. No caso das empresas de aplicativo de transporte, por exemplo, os motoristas apenas precisam ter habilitaçáo para dirigir, sem que seja necessário o conhecimento de trajetos, ruas, pontos turísticos, mapa da cidade, direção defensiva ou segurança no transporte de passageiros. Basta se cadastrar e dirigir sem nenhuma exigência prévia em termos de aperfeiçoamento para desempenho de uma função específica que seja oferecida pela plataforma. Além disso, essas empresas se apresentam como ferramentas colaborativas que permitem que usuários, clientes e prestadores de serviço se encontrem. Contudo, essa característica "colaborativa" perde seu efeito na medida em que a empresa, além de ser a única que determina as regras e valores pagos aos trabalhadores - presumidamente - autônomos, ainda lucra com o trabalho dos mesmos, o que descaracteriza a "colaboração" e caracteriza a eficiência capitalista deste modelo.

Este trabalho é conhecido como on-demand, porque o motorista é acionado para viagens, à medida que a empresa direciona para ele as chamadas solicitadas pelos passageiros. A partir da realização da viagem, o motorista recebe um percentual sobre o valor determinado para o trajeto. Este valor depende não só da distância, como também do horário e da quantidade de motoristas e clientes disponíveis. Sob total controle da empresa, todos esses dados, chamados de algoritmos, são cruzados de forma a determinar os valores de precificação do trabalho prestado. Ou seja, é o algoritmo que gerencia o processo produtivo dos motoristas. Além desse controle, as regras e o processo de cadastramento e descadastramento da plataforma também acontecem sem interferência dos trabalhadores e todos os custos e investimentos necessários para a execução do trabalho são por conta dos motoristas.

Embora as atividades laborais em aplicativos apresentem questôes que indicam que a mesma é desvantajosa para os trabalhadores, a adesão às plataformas de aplicativo vem crescendo em todo o mundo, sinalizando que os trabalhadores conseguem enxergar vantagens na atividade. Isso se dá porque o mercado informacional parte de conceitos basilares que preconizam um modelo que proporciona oportunidade de trabalho sem burocracia, com recebimento imediato. Além disso, constroem sentidos e acessam valores que se relacionam com expectativas, necessidades, desejos,

$9 \quad$ PSPP é um software livre de tratamento de dados estatísticos, disponibilizado gratuitamente, criado para ser alternativa

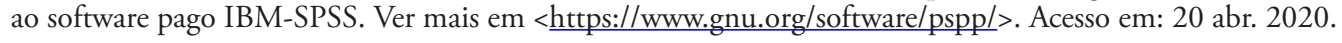


emoçôes e racionalidades que dialogam com questóes urgentes da vida dos trabalhadores. A persistente situação de instabilidade do mercado de trabalho brasileiro (VARGAS, 2014) é uma das questóes que contribui para a determinação desses valores e sentidos, assim como o avanço do neoliberalismo - que se baseia em uma racionalidade na construção do indivíduo por si mesmo afetando a subjetividade dos trabalhadores.

O que está em jogo nesses exemplos é a construção de uma nova subjetividade, o que chamamos de "subjetivação contábil e financeira", que nada mais é do que a forma mais bem-acabada da subjetivação capitalista. Trata-se, na verdade, de produzir uma relação do sujeito individual com ele mesmo que seja homóloga à relação do capital com ele mesmo ou, mais precisamente, uma relação do sujeito com ele mesmo como um "capital humano" que deve crescer indefinidamente, isto é, um valor que deve valorizar-se cada vez mais (DARDOT; LAVAL, 2016, p. 31).

Deste modo, é de suma importância que se desenvolvam análises sociológicas para compreensão do fenômeno que se relaciona com esta modalidade de trabalho e que está interferindo na vida dos trabalhadores pois forja novas relaçóes econômicas e de trabalho.

Considerando que a pesquisa utilizou a empresa Uber como referência, as informaçôes que a mesma fornece em seu site foram coletadas para ajudar na compreensão sobre este mercado. No que se refere à adesão dos trabalhadores, a empresa divulga alguns números que são importantes de serem registrados e que ajudam a compreender o crescimento do setor no Brasil e no mundo. Embora as informaçôes do site da empresa não sejam confiáveis como dados empíricos, são uma fonte referencial sobre o que a empresa comunica a seus "colaboradores" potenciais e ao mercado.

Tabela 1 - Uber em números: 60 países (fundação em 2010 e chegada ao Brasil em 2014)

\begin{tabular}{|c|c|c|c|}
\hline & Cidades & Motoristas parceiros & Usuários \\
\hline Brasil & 100 & $600 \mathrm{mil}$ & 22 milhões \\
\hline No mundo & 700 & 3 milhões & 93 milhões \\
\hline
\end{tabular}

Fonte: Uber (2020).

As informaçóes motivacionais que constam no site dizem muito sobre as expectativas que são construídas em torno da atividade: dinheiro rápido, sem burocracia, liberdade de horários, oportunidades progressivas, independência financeira e autonomia. Por outro lado, não são mencionados, de forma clara, os comprometimentos e custos financeiros necessários para execução da atividade. Essa é uma comunicaçáo parcial e difusa que faz parte do conceito de empresa de capital informacional que se relaciona com questôes valorosas aos trabalhadores que buscam independência, liberdade e empreender a partir de si mesmos como modo de vida (ZUKERFELD, 2020).

\section{A RELAÇÃO ENTRE A UBERIZAÇÃO E FLEXIBILIZAÇÃO DO TRABALHO}

Os dados oficiais obtidos pela Pesquisa Nacional por Amostra de Domicílios - Contínua (PNAD) do Instituto Brasileiro de Geografia e Estatística (IBGE) não fornece informaçôes específicas sobre a atividade por aplicativo - ou sobre essa população-alvo - mas, sim, sobre motoristas em geral, tornando possível construir apenas uma correlação parcial dos dados. Na PNAD de dezembro de 2019, há a informaçáo de que houve um aumento de quase 30\% entre 2017 e 2019 
na quantidade de "pessoas que trabalham em veículos ${ }^{10}$ ", sendo o maior valor da série histórica ${ }^{11}$ desta pesquisa. Este dado revela o fato já mencionado de que há um crescimento significativo na adesáo à atividade. Mas como explicar este crescimento quando se associa a atividade à precarização do trabalho?

A tecnologia traz consigo a modernização no mercado e nas relações de trabalho, sem necessariamente significar relaçóes de trabalho mais justas e equânimes com esse desenvolvimento. $\mathrm{O}$ documentário Uberização da Vida (UBERIZAÇÃO, 2020) mostra como a atividade precariza e subordina o trabalho ao capital financeiro. Os trabalhadores se expóem a uma atividade sem vínculo contratual, em uma rotina exaustiva, com ganhos reduzidos, obrigados a usar seus recursos próprios para trabalhar, sem organizaçáo social efetiva que defenda seus interesses, dentro de uma lógica desenvolvimentista em detrimento da sobrevivência precarizada do trabalhador (FONTES, 2020). Deste modo, são essas duas as principais características que definem a uberização: os trabalhadores assumem os riscos e custos e não possuem contrato de trabalho. Complementando este quadro, a uberização também reorganiza as relações trabalhistas e o próprio mercado de trabalho através de novas formas de controle e gestão, baseados na tecnologia, que promovem a fiscalização constante desses trabalhadores, tornando-os subordinados aos interesses da empresa sem serem funcionários da mesma.

Isso não significa que a precarização das relações de trabalho seja causada pela uberização. A precariedade das relaçóes de trabalho no Brasil é uma questão inerente ao nosso mercado de trabalho e tem uma trajetória histórica. Mesmo considerando que houve alguma melhoria a partir dos anos 2000, essa condição de instabilidade é familiar para o trabalhador brasileiro. O que vemos agora é um agravamento dessa situação (VARGAS, 2014) ${ }^{12}$. Sendo assim, o que se pode associar é o fato de que a Uber chega ao Brasil neste momento de agravamento da situaçáo para a classe trabalhadora. Considerando este contexto, a uberizaçâo pode ser considerada como uma atividade que contribui para a reprodução dessa condição desfavorável e exacerba a precarização no mundo do trabalho. A partir das mudanças na economia brasileira, há pistas importantes para um nexo causal entre o crescimento dessa modalidade informacional de trabalho e o aumento do desemprego e do trabalho informal no mesmo período. Esta é uma situação que contribui para compreender a adesão dos trabalhadores a uma atividade que apresenta significativas desvantagens. Por outro lado, provê trabalho e renda de forma relativamente rápida, em um momento de escassez e de necessidades urgentes.

\section{OS APLICATIVOS QUE OS MOTORISTAS USAM}

Atualmente, a Uber não é mais a única empresa no mercado de aplicativos para transporte de passageiros. Por isso, é relevante saber com quantos e com quais aplicativos os motoristas estáo

\footnotetext{
$10 \quad$ Quando a PNAD se relaciona sobre "populaçáo que trabalha em veículos", ela se refere a motoristas em geral, o que configura motoristas de aplicativo, taxistas e também motoristas e trocadores de ônibus. Sendo assim, os números não expressam dados referentes aos motoristas de aplicativo especificamente (CRELIER; IBGE, 2019).

$11 \quad$ Aumento de 29,2\% em 2018, representando 810 mil pessoas a mais em relação a 2017. É a maior alta desde 2012: "As recentes altas podem estar relacionadas ao crescimento dos serviços de transportes de passageiros e de entregas por aplicativos de celular, refletindo as mudanças na economia atual”, segundo a pesquisadora do IBGE Adriana Beringuy (CRELIER; IBGE, 2019).

12 De acordo com Francisco Vargas (2014, p. 185), "O emprego constitui-se como meio fundamental de acesso à renda à proteção e ao reconhecimento social através da atividade econômica considerada legítima. É nestes termos que a questão do emprego se torna também uma 'questão social' e não apenas uma 'questão econômica'”.
} 
trabalhando. As respostas revelaram 40 empresas ${ }^{13}$ de aplicativos sendo utilizadas. Em muitos casos, revela também que os motoristas trabalham com mais de uma empresa ao mesmo tempo. As duas empresas mais citadas configuram um monopólio importante que pode interferir nas políticas de remuneração desses trabalhadores, permitindo que essas empresas dominem as regras do mercado.

A Uber se confirmou como a empresa de aplicativo líder do mercado. No survey, a ela obteve 686 citaçóes, e o aplicativo "99 Taxi”" ${ }^{4}$ ficou em segundo lugar, com 573 citaçóes. Essa situação também indica que o uso de uma empresa de aplicativo não é capaz de prover a renda necessária para estes trabalhadores. Somado a isso, o uso de mais aplicativos ao mesmo tempo também representa um maior volume de trabalho e estresse para administrar a demanda de passageiros de duas ou mais fontes distintas.

Uma das razóes pelas quais os motoristas utilizam mais de um aplicativo se relaciona com o fato de que há um tempo de espera entre as chamadas que é longo o suficiente para justificar o uso de outro aplicativo. Este tempo de espera significa trabalho não remunerado, que não é controlado pelo motorista, e o uso de outro aplicativo é a forma encontrada para compensar este tempo ocioso, na tentativa de torná-lo rentável. Outra questáo para o uso de mais de um aplicativo se relaciona com a quantidade de motoristas disponíveis, pois a empresa não limita o número de motoristas, sendo assim, com o aumento da crise do emprego, aumenta o cadastramento no serviço de aplicativo e diminui a quantidade de corridas para cada trabalhador, levando em conta que o número de clientes não aumenta na mesma proporção. Em tempo, é importante citar que este período ocioso e não remunerado caracteriza disponibilidade do trabalhador para a empresa de aplicativo, da qual ele não é funcionário. Apesar de as empresas de aplicativo insistirem em afirmar que o trabalhador cadastrado ou "parceiro" tem a liberdade para escolher quando e quanto tempo vai trabalhar ${ }^{15}$, a situação não é bem assim. Na realidade, a empresa é que determina quando o motorista vai trabalhar e quanto ele vai ganhar, desde que ele ligue o aplicativo e esteja disponível e esperando ser chamado (on-demand).

Karl Marx (2015) explica com bastante exatidão a exploração do trabalhador e a premissa da acumulação do capital a partir do conceito de mais-valia. A teoria marxiana argumenta que este tempo ocioso é o mais-valor que gera a acumulação de capital, o propósito primordial do sistema capitalista. Isso porque o trabalhador vive da venda de sua força de trabalho e o valor do trabalho é incorporado no valor da mercadoria produzida. $\mathrm{O}$ excedente da força de trabalho ou tempo de trabalho efetivo e náo remunerado caracteriza o mais-valor, que é o lucro gerado pelo excedente de

13 Das 40 empresas citadas pelos/as motoristas, apenas oito foram mencionadas com maior frequência. O mercado possui grande número de pequenos aplicativos como alternativa ao uso das grandes empresas, mas seu uso ainda é inexpressivo como concorrência. Quatro aplicativos foram citados até 50 vezes, incluindo aplicativos de entrega de comida. Isso demonstra que os motoristas estão também entregando comida com o uso do carro, revelando mais uma forma de aumentar a remuneração. Apenas dois aplicativos tiveram até 150 citaçóes, uma quantidade bem inferior às duas principais empresas, confirmando quem lidera o mercado (BESSA, 2020).

14 O aplicativo 99TAXI é voltado para taxistas que desejam trabalhar ou sentem necessidade de prover corridas nas mesmas condiçóes das empresas de aplicativo. Além de explicitar a questão da concorrência dentro do mercado de transporte de passageiros, o aplicativo para taxistas mostra que essa nova modalidade impacta, interfere e precariza o mercado formal de trabalho dos táxis. Considerando que o trabalho do taxista é autônomo, formal e regulamentado, a migração para o aplicativo significa informalidade e perda da autonomia, portanto precarização (BESSA, 2020).

15 No site da empresa é possível encontrar narrativas incentivadoras para o exercício da atividade onde o trabalhador encontrará liberdade e renda: "Para quem dirige ou entrega por meio da plataforma, a Uber representa uma forma flexível de gerar renda” (UBER, 2020, online). 
trabalho que o capitalista recebe do trabalhador, mas não paga por ele. $\mathrm{O}$ excedente de trabalho, no caso das plataformas, pode ser interpretado como a disponibilidade não remunerada gerada pela espera entre as chamadas do aplicativo. Deste modo, a empresa de aplicativo não tem funcionários, mas tem força de trabalho disponível e não remunerada sempre que ela precisa atender seus clientes.

A baixa remuneração, concomitantemente a não-remuneração, também é determinante para o uso de mais de um aplicativo. Isso porque quanto mais motoristas disponíveis, menos corridas são disponibilizadas e as empresas pagam taxas menores por trajeto. Sendo assim, a necessidade de procurar mais clientes através de outros aplicativos é a forma que os motoristas encontram de aumentar a renda auferida na atividade ou mesmo a possibilidade de auferir alguma renda nos dias de pior movimento. Desta forma, ao considerar a diferença entre as citaçóes das principais empresas (113 citaçóes), pode-se intuir que apenas 15\% dos respondentes utilizam só um aplicativo. Ou seja, $85 \%$ desses trabalhadores usam mais de um aplicativo ao mesmo tempo, indicando que, em alguma medida, a remuneração é insuficiente para o tempo de dedicação à atividade e há a necessidade de buscar mais clientes.

\section{O DESEMPREGO E O MERCADO DE TRABALHO}

O desemprego é uma questão que se relaciona com o mercado informal de trabalho e consequentemente com a modalidade uberizada de trabalho. A conjunção entre desemprego e uberização do trabalho diz respeito não somente em relação à crise econômica, mas também quando se consideram as mudanças que acompanham o desenvolvimento tecnológico. Os trabalhadores lidam com questóes relacionadas à crise - que fecha postos de trabalho - e também com as questóes que envolvem a automatização de atividades laborais que deixam de existir ou que passam a exigir novas qualificaçóes para seu desempenho. Somado a isso, a velocidade dessas transformaçóes nem sempre são passíveis de serem acompanhadas pelo desenvolvimento educacional para aprendizado dessas novas habilidades requeridas, posto que o processo educacional e de aprendizado é mais lento que o desenvolvimento informacional e tecnológico sendo, portanto, uma situação complicada quando vista pelos comprometimentos que representa para a classe trabalhadora.

Em 2016, segundo o IBGE, 28 milhôes de pessoas ficaram sem trabalho no país, o pior resultado em 11 anos (UOL, 2016). A situação de crise econômica reflete no mercado de trabalho um movimento no sentido de promover providências visando à flexibilização das leis trabalhistas e o incentivo à terceirização e ao empreendedorismo: providências que são justificadas por políticas neoliberais como sendo necessárias para reduzir os gastos com funcionários e aumentar a disponibilização de novas vagas de trabalho. Essa melhoria no mercado não se confirma e mesmo com a flexibilização a crise do emprego só vem aumentando. Desta forma, pode-se considerar que o desemprego é nada mais que uma justificativa para a precarização do trabalho formal e da redução dos direitos e proteçôes sociais dos trabalhadores. Para Abilio (2019, p.4), "no contexto da flexibilização do trabalho, implementação de políticas neoliberais e aumento do desemprego, a definição de empreendedorismo vem adquirindo novos usos e significados políticos". Esta é uma situação que coloca o trabalhador em vulnerabilidade e retira direitos e proteçóes sociais de postos de trabalho formais. Uma forma de enfrentar é quando ele se torna o único responsável por dar conta de suas necessidades e dificuldades em um contexto social de incertezas e sobre o qual ele não tem agência. 
Neste contexto, a atividade por aplicativo se apresenta como amparo a este trabalhador que não consegue encontrar colocação no mercado de trabalho e precisa de renda para suas necessidades urgentes de sobrevivência. Entretanto, como já mencionado, essa é uma realidade histórica do mercado de trabalho. De modo algum é possível afirmar que essa é uma realidade causada pela sociedade pós-industrial ou mesmo que seja algo que somente passou a acontecer na atualidade. O que temos é, em realidade, uma situação que o desenvolvimento tecnológico e o capitalismo informacional apenas exacerbam. Por outro lado, pode-se dizer que esse agravamento da situação é muito mais veloz e agressivo como em nenhuma outra época. Pochmann (2020) relata que há um ataque contínuo ao trabalho formal no Brasil e uma expansão descontrolada do mercado de capital. Situação essa que estimula o desenvolvimento do mercado de serviços, como é o caso dos aplicativos. Uma situação que significa desestruturação econômica, social e trabalhista:

Desde os anos de 1990 que o esgotamento da industrialização vem dando lugar a outro sistema econômico assentado nos serviços sob a dominância do rentismo financeiro ao lado da dependência da produção e exportação de produtos primários. Com essa transformação na infraestrutura produtiva, a estrutura da sociedade salarial passou a sofrer as consequências do enxugamento tanto da classe média assalariada como da velha classe trabalhadora industrial (POCHMANN, 2020, p. 83).

Concluindo essas colocaçóes prévias, a atividade por aplicativo e a precarização do trabalho podem ser relacionadas quando vistas a partir do desmonte das leis trabalhistas, conjuntamente com as políticas neoliberais que se aprofundaram no país desde 2016. São questôes que ainda não permitem conclusôes exatas, mas possibilitam fazer algumas conexóes causais. Polanyi (2000) nos traz conceitos que explicam essa mudança a partir das transformaçóes do capital na sociedade. A criação do mercado liberal e a industrialização definiram as normas que regem a economia e o mercado de trabalho. Esse novo modelo é baseado na racionalidade e promove o rompimento com a organização social, pois coloca o desenvolvimento econômico como prioridade, moldando novas relaçôes sociais, alterando as subjetividades. A questão relevante a se considerar fica sendo, então, o impacto provocado por essa sociedade informacional nos modos de vida dos trabalhadores, baseada em uma lógica mercantil e economicista: uma lógica que interfere na mentalidade dos sujeitos e contribui para explicar porque os trabalhadores aceitam condiçóes desfavoráveis à sua sobrevivência, mas que são favoráveis às leis de mercado.

\section{O PERFIL DOS MOTORISTAS DE APLICATIVO}

O objetivo desta seção é apresentar as descriçôes do perfil dos indivíduos que exercem a atividade por aplicativo, considerando o contexto socioeconômico e político vigente em nossa sociedade, sem aprofundar nas questôes que foram tratadas nas outras partes da pesquisa. Através das respostas obtidas no questionário, o propósito é construir análises sociológicas que permitam compreender melhor o campo considerando as implicaçôes nos modos de vida dos trabalhadores. $\mathrm{O}$ recorte sobre o perfil do motorista de aplicativo propóe uma análise a partir de variáveis como estado civil, idade, região, motivaçóes, sexo/gênero, complementadas pela descrição da atividade e pela conjuntura no mercado de trabalho. 


\section{ORIGEM E MIGRAÇÃO}

Ressalta-se que a representação do território nacional nesta pesquisa se deu através da escolha das cidades onde a Uber atuava - no momento da consulta - em todo o Brasi ${ }^{16}$. Todas as cidades da lista foram buscadas para análise. É importante ressaltar também que, embora as regiôes não estivessem representadas de forma igualitária em número de cidades ou nem todas as cidades tivessem grupos no Facebook ou, ainda, nem todos os grupos tivessem o mesmo movimento, esse cenário é baseado em uma representação que há do mercado no território nacional no que se refere à empresa de maior expressão no mercado, inclusive concebendo suas diferenças de presença em determinadas regiōes e/ou cidades do Brasil. Desta forma, foi considerado que essa representação se refere ao cenário brasileiro, em boa medida, tal e qual ele se apresentava naquele momento.

A localização dos indivíduos que atuam na atividade é uma informação que foi analisada a partir de três variáveis: onde os indivíduos nasceram, onde moram e onde trabalham. O objetivo foi verificar se havia transição de um local para o outro que pudesse ser relacionada ao exercício da atividade.

Tabela 2 - Local de nascimento versus local onde moram, em percentuais (\%).

\begin{tabular}{|c|c|c|c|c|c|}
\hline & SP & RJ & SC & RS & PR \\
\hline NASCIMENTO & 15,27 & 13,05 & 5,48 & 11,62 & 10,05 \\
\hline MORADIA & 14,62 & 12,40 & 10,57 & 9,66 & 9,53 \\
\hline
\end{tabular}

Fonte: trabalho de campo.

As respostas mostraram que os trabalhadores que nasceram nos estados de São Paulo (SP), Rio de Janeiro (RJ), Rio Grande do Sul (RS) e Paraná (PR), correspondem a 50\% dos respondentes, revelando a predominância do exercício da atividade nas Regiôes Sul e Sudeste ${ }^{17}$. Por outro lado, uma parte relevante, composta por $45 \%$ dos respondentes, nasceu ou moram nas demais regióes do país.

16 Lista de cidades do Brasil onde a Uber atua e que foram pesquisadas: - Regiáo Sudeste (Araçatuba, Bauru, Botucatu, Bragança Paulista, Campinas, Franca, Marília, Mogi Guaçu, Piracicaba, Presidente Prudente, Ribeirão Preto, Santos, São Carlos, São José do Rio Preto, São José dos Campos, São Paulo, Sorocaba, Angra dos Reis, Cabo Frio, Campos dos Goytacazes, Macaé, Nova Friburgo, Petrópolis, Rio de Janeiro, Volta Redonda, Barbacena, Belo Horizonte, Cachoeiro de Itapemirim, Conselheiro Lafaiete, Divinópolis, Governador Valadares, Ipatinga, Juiz de Fora, Linhares, Montes Claros, Patos de Minas, Poços de Caldas, Pouso Alegre, Uberaba, Uberlândia, Varginha, Vitória) - Regiāo Sul (Blumenau, Cascavel, Caxias do Sul, Chapecó, Criciúma, Curitiba, Florianópolis, Foz do Iguaçu, Guarapuava, Itajaí, Joinville, Lages, Londrina, Maringá, Passo Fundo, Pelotas, Ponta Grossa, Porto Alegre, Santa Cruz do Sul, Santa Maria) - Regiōes Norte e Nordeste (Aracaju, Arapiraca, Belém, Boa Vista,Campina Grande, Caruaru, Feira de Santana, Fortaleza, Imperatriz, Itabuna, Ilhéus, João Pessoa, Juazeiro do Norte, Macapá, Maceió, Manaus, Marabá, Mossoró, Natal, Parauapebas, Petrolina, Porto Seguro, Porto Velho, Recife, Rio Branco, Salvador, São Luís, Sobral,Teresina, Vitória da Conquista) - Região Centro-oeste (Brasília, Campo Grande, Cuiabá, Dourados, Goiânia) (BESSA, 2020).

17 O movimento mais consistente aconteceu nos grupos do Facebook do RJ e SP. O RJ apresentou grupos que somavam, aproximadamente, 60 mil integrantes, um número muito superior aos demais grupos no Brasil. Um grupo de Recife (PE) contava com 30 mil integrantes mas, apesar do número considerável, não apresentou movimento suficiente para dar representatividade à Região Nordeste. Os grupos de SP não eram tão expressivos em número de integrantes como os citados anteriormente. Em contrapartida, o estado tinha um maior número de cidades com grupos que apresentavam boa movimentaçáo. No RJ, a movimentação se concentrou em poucas cidades, incluindo a capital e algumas poucas da região metropolitana. Sendo assim, como os grupos do Facebook podem não corresponder a uma fiel realidade em termos de representatividade, é possível considerar que os trabalhadores de fora da Região Sudeste possam estar sub-representados nesta pesquisa. Contudo, é relevante ressaltar que essa sub-representaçáo também pode expressar a forma como o mercado se apresenta nas regiốes e, assim, expressar como a população se revelou através da participação no questionário, reforçando que pode ser considerada a formação de como o cenário brasileiro se mostra na atividade (BESSA, 2020). 
A migração dos respondentes em função da busca por trabalho e renda pôde ser verificada, em certa medida, pelas perguntas sobre localidade de nascimento e localidade de trabalho. Os trabalhadores responderam que moram, predominantemente, nas Regióes Sul e Sudeste do país (SP/RJ com $28 \%$ e SC/RS/PR com 30\%). O que parece demonstrar que não houve uma migração considerável entre regiôes. Se houve, não foi perceptível nos números. As respostas sobre onde trabalham (ou "rodam") revelaram que a maioria trabalha nas capitais em todas as Regióes do país. Apenas SP mostrou que há maior circulação também em outras cidades do Estado, de forma geral. As respostas demonstraram que a atividade por aplicativo apresenta a possibilidade de trabalho e obtenção de renda na regiáo onde esse trabalhador nasceu ou onde mora (exceto RS).

Tabela 3 - Movimentação entre os 6 estados mais citados

\begin{tabular}{|c|c|c|c|}
\hline ESTADOS & NASCIMENTO & MORADIA & ONDE RODA \\
\hline SP & 117 & 112 & 105 \\
\hline RJ & 100 & 95 & 93 \\
\hline RS & 89 & 74 & 10 \\
\hline PR & 77 & 73 & $X$ \\
\hline MG & 54 & $X$ & $\mathbf{5 0}$ \\
\hline SC & $\mathrm{X}$ & 81 & 78 \\
\hline
\end{tabular}

Fonte: trabalho de campo.

O que pode ser um fator que leva os trabalhadores a escolher atuar na atividade, uma vez que, sem necessidade de deslocamentos significativos, há menor necessidade de gastos e de alteração da rotina familiar ou afastamento entre os trabalhadores e suas famílias. Essas consideraçóes são importantes porque o deslocamento, principalmente de natureza permanente, requer despesas e investimentos que o trabalhador, que busca atuar neste tipo de atividade, não tem para dispor. Além disso, a falta de trabalho compromete não somente a vida financeira, como também pode causar afastamento e interferência na convivência familiar.

O trabalho sem deslocamento tem um valor, pois significa trabalho imediato. O imediatismo da atividade por aplicativo confere uma relativa autonomia para este trabalhador e pode resolver questóes urgentes de trabalho e renda. Ele pode conseguir trabalho sem muitas exigências burocráticas ou significativos deslocamentos. Essa facilidade relativa também confere um tipo de protagonismo para mudar a sua situação, sem mediação patronal explícita, o que também atende a esta demanda individual do trabalhador que se encontra sem ocupação e com necessidades urgentes a suprir. Por outro lado, este imediatismo revela um individualismo que é reflexo das mudanças que o capitalismo trouxe para o mundo do trabalho, como afirma Sennett (2009). Para Sennett, essa alteração afeta também o caráter do trabalhador, individualizando-o perante a coletividade e afetando a percepção das consequências no longo prazo. O momento imediato é definidor de suas decisóes. Sem os velhos modelos de construção de carreira, estabilidade, e burocracia, trabalhadores moldados por inseguranças buscam novos modelos que os faça sentir ter o controle sobre suas vidas.

\section{GÊNERO, RAÇA/COR, CONJUGALIDADE E DEPENDENTES}

Os dados sobre gênero, raça ou cor, conjugalidade e dependentes são sensíveis na definição do perfil de uma classe trabalhadora, pois permitem delinear o conjunto de características desses 
indivíduos e de seus modos de vida. No caso da atividade por aplicativo, a questão de gênero ficou bem delimitada. $\mathrm{O}$ gênero predominante é o masculino. As respostas mostraram que $80 \%$ dos motoristas são homens, situação que foi percebida também nos grupos do Facebook ${ }^{18}$.

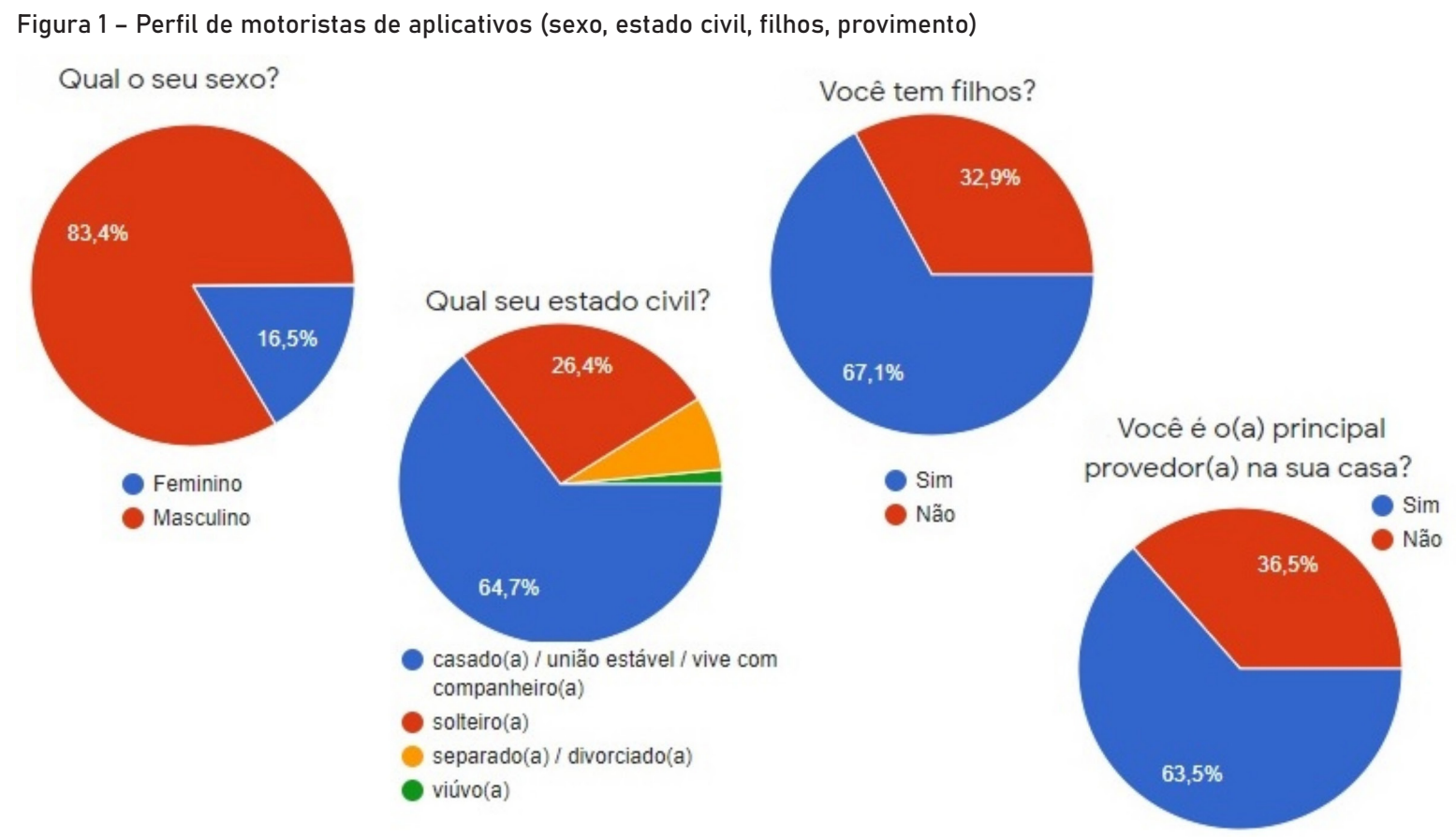

Fonte: trabalho de campo.

No que se refere à conjugalidade, a maioria dos respondentes (65\%) declararam que são casados, em união estável ou vivendo com o/a companheiro/a. Além disso, 67\% declararam que têm filhos e que $64 \%$ são os principais provedores de suas famílias. Ou seja, esses trabalhadores têm família constituída, possuem dependentes e responsabilidades sobre a sobrevivência de terceiros. Diante desses dados, pode-se verificar que também há uma questão relacionada ao estresse familiar gerado pelo desemprego e pela desocupação que mantém esse homem dentro de casa. Um trabalho rápido, mesmo com renda insuficiente, é melhor que ficar em casa parado. Somado a isso, o fato de não ser necessário migrar para exercer a atividade é ponto positivo para este perfil de trabalhador. Isso diz bastante sobre o sentido que a atividade possui dentro destes contextos. Bezerra (2019) observou em depoimentos de motoristas o valor que o trabalho representa além da sobrevivência quando se fala de família, pois estes trabalhadores se sentem úteis, com maior dignidade e com mais possibilidades de realizarem seus sonhos e das pessoas com quem mantém relações de parentesco.

\footnotetext{
18 Dados da UBER dão conta que apenas 6\% dos/as "colaboradores/as" são mulheres (UBER, 2020). A presença reduzida de mulheres na atividade pode estar relacionada com a violência contra a mulher ou com a acumulação de funçóes de trabalho doméstico, cuidados familiares e com a maternidade. São questóes que interferem na escolha pelo trabalho por aplicativo ou na exclusão expressiva da mulher também em outras atividades no mundo do trabalho, podendo ser fruto de uma investigação mais aprofundada e que os dados dessa pesquisa náo foram suficientes para responder (BESSA, 2020).
} 
Figura 2 - Perfil de motoristas de aplicativos (raça)

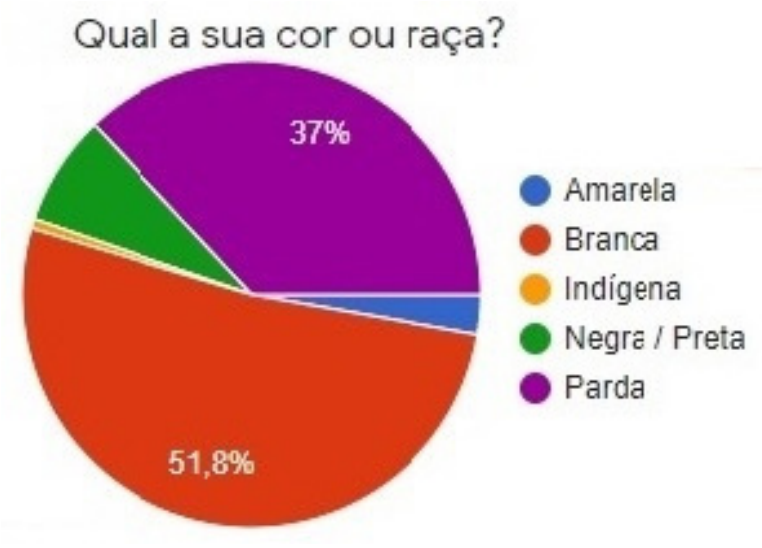

Fonte: trabalho de campo.

No que se refere a cor ou raça dos respondentes, mais de $52 \%$ se declararam brancos e quase 45\% são pardos ou pretos. $\mathrm{Na} \mathrm{PNAD} / 2018$ do IBGE, assim como na pesquisa, as respostas de quem se declarou da cor parda foram maiores que os que se declararam da cor preta. Por outro lado, nesta pesquisa, a porcentagem de brancos foi maior que a de pretos e pardos somados. Esses dados podem ser aprofundados em pesquisas posteriores quando relacionados às desigualdades sociais, desemprego e informalidade no mercado de trabalho. Nesta pesquisa, assim como na PNAD/2018, os motoristas autodeclarados pardos foram em número superior aos autodeclarados pretos. Por outro lado, ainda assim, somados pretos e pardos, a população autodeclarada branca tem maior presença na atividade, segundo as respostas. Na PNAD, as informaçóes mostram que a maioria da populaçáo fora da força de trabalho, desocupada e subutilizada é autodeclarada preta ou parda. De modo que, ao considerar que a pesquisa monográfica apresenta uma maior populaçáo autodeclarada branca, para fazer relação ao desemprego como motivação para o desempenho da atividade, é necessário fazer cruzamentos entre outros dados como escolaridade, desemprego formal e trabalho informal para adensar a análise.

\section{IDADE E ESCOLARIDADE}

A idade dessa população é importante para entender a compatibilidade com o perfil do trabalhador com sua situação conjugal, ou com o nível de responsabilidades que ele possui. $\mathrm{O}$ dado sobre escolaridade, além de poder se relacionar com a situaçáo socioeconômica do indivíduo, revela a possibilidade de dedicação aos estudos, quais as habilidades e nível formal de conhecimento atingido por este trabalhador. Complementarmente, permite confrontar esses resultados com o exercício de uma atividade laboral que exige baixa capacitação. 
Figura 3 - Perfil de motoristas de aplicativos (idade)

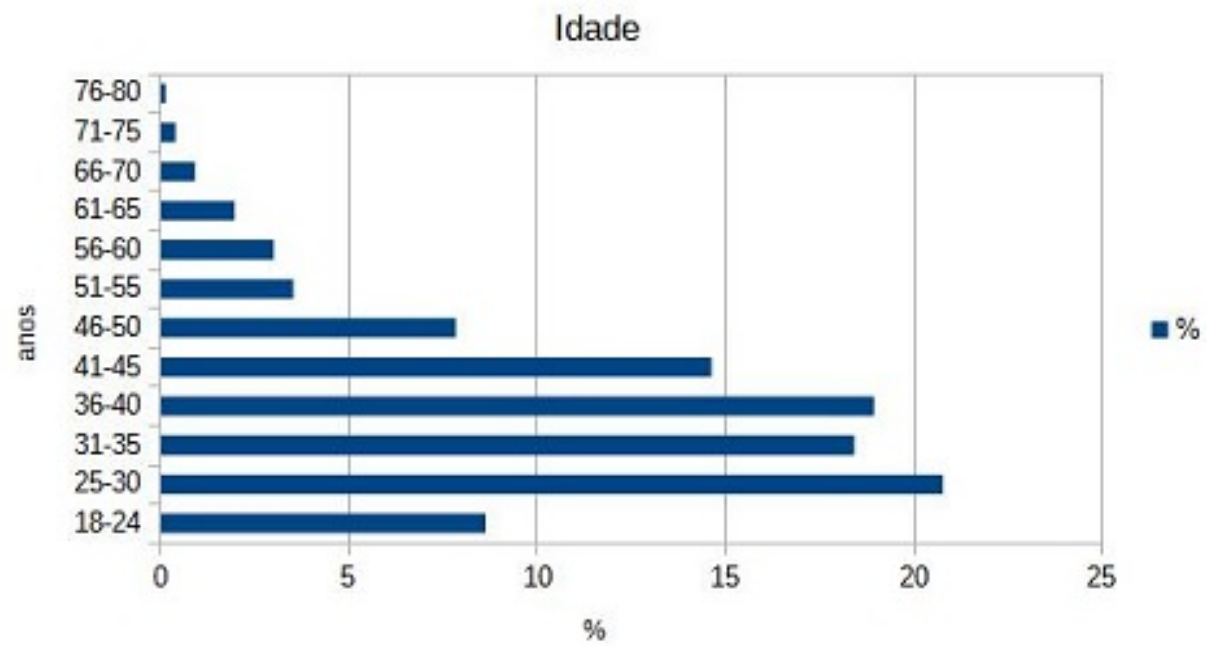

Fonte: trabalho de campo.

Os motoristas respondentes da pesquisa revelaram indivíduos de idade bastante variada, entre 19 e 73 anos. Fazendo uma análise mais apurada nos dados, separando por faixas etárias, menos de $10 \%$ são menores de 24 anos, $15 \%$ estão entre 43 e 50 anos, e $10 \%$ estão entre 51 e 73 anos. A faixa de idade que concentrou maior número de respondentes foi dos 25 aos 42 anos e corresponde a $65 \%$ da amostra. Esse dado se relaciona diretamente com o fato de uma maioria entre os respondentes ser casada e com filhos, pois a idade média de 33 anos constatada na pesquisa está próxima da idade média de 31 anos que os homens se casam, segundo aponta o IBGE (2019).

A escolaridade não somente revela o tempo de permanência dos indivíduos na escola, como também a relação com as oportunidades que o indivíduo teve para se desenvolver intelectualmente e profissionalmente. Sendo assim, a escolaridade é igualmente relevante, pois permite relacionar o nível educacional formal na atividade por aplicativo com o nível de desemprego, considerando que a escolaridade pode sinalizar que este trabalhador saiu de um trabalho formal ou de uma posição socialmente mais elevada - devido à sua formação - para atuar em uma atividade informal e com menor exigência de capacitação. No que se refere à escolaridade, 50 \% declarou possuir boa escolaridade (superior completa ou incompleta). 
Figura 4 - Perfil de motoristas de aplicativos (idade)

Qual a sua escolaridade?

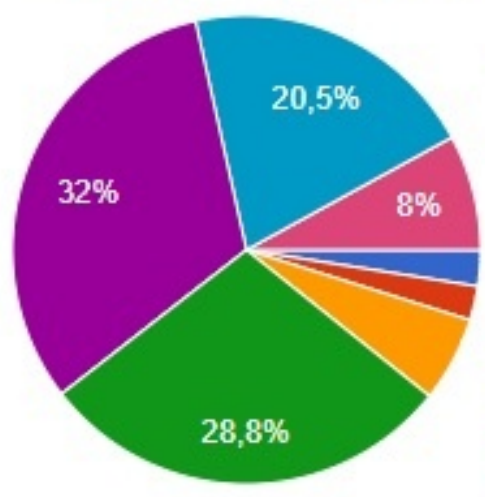

Fundamental incompleto (não terminou o $9^{\circ}$ ano )

Fundamental completo (terminou o $9^{\circ}$ ano)

Ensino médio incompleto (não terminou o $3^{\circ}$ ano do ensino médio)

Ensino médio completo (terminou o $3^{\circ}$.

Superior Incompleto (não terminou a f...

Superior completo (terminou a faculda..

Pós-graduado (formação após conclu...

Fonte: trabalho de campo.

Analisando estes números à luz dos dados censitários, observa-se uma coerência quando considerado os resultados sobre raça. A PNAD de 2018 reproduz uma realidade brasileira onde a maioria de raça branca, como declarado nesta pesquisa, também possui maior grau de escolaridade. Essa informação também pode ser relacionada com a questão do desemprego por falta de vagas e oportunidades no mercado formal, uma vez que são pessoas que podem ter tido maior possibilidade de acesso ao estudo, com maior graduaçáo e melhores posicionamentos no mercado de trabalho.

\section{MOTIVAÇÕES PARA O EXERCÍCIO DA ATIVIDADE}

Para além dos dados quantitativos ou das questóes estruturais - econômicas, políticas e sociais - é importante entender os sujeitos como pessoas capazes de decidir e fazer escolhas. Compreender a complexidade das alteraçóes nas mentalidades, no mercado de trabalho, compreende também entender os indivíduos que participam dessa realidade social e econômica e interagem dentro delas. Em alguma medida, as motivaçóes pessoais estão diretamente relacionadas com as decisóes que são tomadas, também sob influência das circunstâncias, o que não retira dos sujeitos sua agência. A motivação nos impele a agir e configura um sentido importante para construção do perfil desses trabalhadores. Por isso, a pergunta feita no questionário foi uma pergunta aberta para que os respondentes pudessem expressar os sentimentos e sentidos que atribuem às suas motivaçóes para exercer a atividade. A título de análise, as respostas foram divididas em três categorias compostas de acordo com o teor das palavras usadas pelos motoristas, como mostra a tabela.

Tabela 4 - Categorização das respostas sobre motivação

\begin{tabular}{|c|c|c|}
\hline RENDA & DESEMPREGO & PESSOAIS \\
\hline $\begin{array}{c}\text { Renda principal ou extra, co- } \\
\text { mida, falta de dinheiro e baixo } \\
\text { salário. }\end{array}$ & $\begin{array}{c}\text { Desemprego, desocupação, de- } \\
\text { sespero, oportunidade, falta de } \\
\text { opção, idade e função obsoleta. }\end{array}$ & $\begin{array}{c}\text { Autonomia, tempo livre, flexibi- } \\
\text { lidade, liberdade, ser o próprio } \\
\text { patrão, consumo, vontade, estu- } \\
\text { do e saúde. }\end{array}$ \\
\hline $36,29 \%$ & $35,24 \%$ & $23,22 \%$ \\
\hline
\end{tabular}

Fonte: trabalho de campo. 
Observa-se uma equiparação entre as categorias renda e emprego. Essa resposta define que a grande motivação para o exercício da atividade é trabalho e dinheiro, ou seja, se essas duas categorias são analisadas como uma só, a resposta é ainda mais contundente, pois $71 \%$ das respostas se referem a estes motivos. Sendo assim, considerando a característica imediatista da atividade capaz de oferecer uma plataforma de trabalho e renda rápidos, as motivações dessa população são, em boa medida, atendidas. Isso não quer dizer que a plataformização seja capaz de suprir as necessidades econômicas dessa populaçáo ou que a atividade configure uma situação de bem-estar e estabilidade financeira para esses trabalhadores, mesmo com uma grande dedicação de tempo a este trabalho.

\section{CONSIDERAÇÕES FINAIS}

Os aplicativos de celular são uma realidade em nossa sociedade e não somente como entretenimento, mas como ferramentas que geram trabalho e renda. A adesão dos trabalhadores a esse tipo de atividade tem crescido em todo o mundo. Levando em conta que este perfil de trabalhador está aderindo a uma atividade cuja lógica prevê ausência de vínculo empregatício, sem proteção social, onde assumem os riscos e gastos para execução do trabalho, mostra-se muito importante buscar entender e interpretar este fenômeno considerando suas peculiaridades e complexidades. Além disso, a tecnologia envolvida no desenvolvimento desses aplicativos também permite controles difíceis de serem percebidos e que impactam o modo de vida dos trabalhadores e sua rotina cotidiana.

A pesquisa conseguiu abranger todas as regióes do país por ter sido realizada pela Internet e foi consideravelmente superior se comparado a uma pesquisa realizada presencialmente, o que foi um ganho para a monografia. O cenário revelado, considerando essa abrangência, é muito interessante para buscar delinear um perfil dos trabalhadores por aplicativo com razoável confiabilidade, considerando que a análise quantitativa associada ao volume de dados obtidos na pesquisa contribui para essa compreensão.

As respostas obtidas a partir do survey distribuído aos motoristas de aplicativo revelaram um perfil bastante detalhado a respeito dos indivíduos que exercem a atividade no Brasil: $80 \%$ são homens, 55\% nascidos e/ou moradores nas Regióes Sudeste e Sul do Brasil, 65\% são casados, 67\% têm filhos, 65\% têm idade entre 25 e 42 anos, 52\% se autodeclararam ser da raça ou cor branca, $52 \%$ têm escolaridade superior completa ou incompleta, $63 \%$ são os principais provedores de suas casas e para $71 \%$ a atividade representa trabalho e renda. Esse perfil configura que há relação concreta entre esses indivíduos e as motivaçóes para o exercício da atividade por aplicativo, uma vez que, homens casados, com boa escolaridade e provedores principais de suas famílias, atuam na atividade em busca de trabalho e renda, dentro de uma situação de falta de ocupação no mercado formal. Uma situação que é persistente na história do mercado de trabalho brasileiro e que, explicitamente, se relaciona com o perfil de pessoas que tem responsabilidades sobre a sua própria sobrevivência e a de outras pessoas com quem convivem.

A narrativa disseminada pela empresa compreende um discurso que define a plataforma como ferramenta colaborativa, que gera trabalho rápido e de forma desburocratizada, provendo renda imediata e com liberdade para o trabalhador. O que não é totalmente inverídico, uma vez que há vantagens que são consideradas por esses trabalhadores. A empresa de fato provê uma atividade que permite um trabalho remunerado, relativamente rápido, na mesma região onde os motoristas moram e sem exigência capacitação prévia ou específica. Somado a isso, provê indiretamente a essa população, mesmo que de forma difusa, o sentimento de protagonismo sobre suas escolhas, sobre seu tempo de dedicação, sem hierarquia patronal e com alguma satisfação para suas necessidades mais urgentes de trabalho e renda, em busca de sustento de si mesmo e de sua família. 
O desemprego e a falta de oportunidades estão diretamente relacionados com a precarização do trabalho que faz parte da história do trabalhador brasileiro. Essa é uma condição persistente de insegurança que configura sentimentos decisivos no momento em que os trabalhadores precisam fazer escolhas. As respostas demonstraram que há predominância de um perfil de trabalhador na atividade por aplicativo que pode ser indicativo de uma exclusão do mercado formal de trabalho - sinalizado pela boa escolaridade da amostra coletada - e que encontra na informalidade e na flexibilização, uma saída para a urgência de renda em um cenário de crise de emprego onde mais de três milhôes de pessoas procuram uma colocaçáo no mercado formal de trabalho há mais de dois anos. Afinal, como indicado nas respostas, são provedores de suas famílias, com dependentes, motivados pelo desemprego.

A busca de oportunidades que possibilitem conquistas - que são prometidas nos discursos da autorrealização e de liberdade individual, presentes no capitalismo informacional - se associam essa realidade histórica de instabilidade persistente do trabalho no Brasil, mesmo diante de poucos intervalos de melhoria dessa condição. Tais características indicam uma relação com o comportamento de individualismo ocasionado pelas transformaçóes capitalistas - que alteram a subjetividade - e estão mais atuantes e presentes na sociedade moderna, do que em qualquer época anterior. Um comportamento que incentiva a crença na agência de um indivíduo supostamente capaz de resolver sozinho suas necessidades de realização pessoal em uma lógica de supremacia de valores economicamente orientados. Uma supremacia econômica que traz a ausência de esclarecimentos sobre os riscos e custos envolvidos, sobre os comprometimentos futuros no que se refere aos direitos sociais e trabalhistas, sobre os controles algorítmicos mais amplos e difíceis de detectar, sobre as sujeiçóes que essas escolhas trazem para o modo de vida desses trabalhadores, contribuindo para produzir e reproduzir uma condição desfavorável e uma precarização do trabalho na sociedade brasileira.

\section{REFERÊNCIAS}

ABILIO, L. C. (2019). Uberização: Do empreendedorismo para o autogerenciamento subordinado. Psicoperspectivas, 18(3). Disponível em <http://dx.doi.org/10.5027/psicoperspectivas-vol18-issue3-fulltext-1674>. Acessado em 25/05/2021.

BESSA, Ana Cláudia. Chama o Uber: as representaçóes do trabalho por aplicativo para os/as trabalhadores/ as brasileiros/as. TCC (Trabalho de Conclusão de Curso em sociologia) - Instituto de Ciências Humanas e Filosofia, Universidade Federal Fluminense. Ana Cláudia Bessa; Cristiano Fonseca Monteiro, orientador; Carolina Castellitti, coorientadora. Niterói, 2020. 90 f.

BEZERRA, Lina Elisabeth Rodrigues. O TRABALHO DO MOTORISTA DE UBER - UMA ALTERNATIVA AO DESEMPREGO ?. Revista Visão: Gestão Organizacional, Caçador, SC, Brasil, p. 0117, jul. 2019. ISSN 2238-9636. Disponível em: <http://dx.doi.org/10.33362/visao.v8i2.1909>. Acessado em 23/02/2020.

DARDOT, Pierre \& LAVAL, Christian. A nova razão do mundo: ensaio sobre a sociedade neoliberal.; tradução Mariana Echalat. - 1. ed. - São Paulo: Boitempo, 2016.

GIL, Antônio Carlos. Métodos e Técnicas de Pesquisa Social. 6a edição. São Paulo: Atlas, 2008. 
MCM TEODORO, TC D'AFONSECA, M Antonieta. Disrupçáo, economia compartilhada e o fenômeno Uber - Revista Faculdade Mineira de Direito, Belo Horizonte, 2017.

MARX, Karl. O Capital: Crítica da Economia Política. Livro I - O processo de produção do capital. Tradução: Rubens Enderle. São Paulo: Boitempo Editorial, 2015.

POLANYI, Karl. A grande transformação.2a ed. Tradução: Fanny Wrabel. Rio de Janeiro: Compus, 2000.

SENNETT, Richard. A Corrosão do Caráter: as consequências pessoais do trabalho no novo capitalismo. Tradução: Marcus Santarrita. 14a edição. Rio de Janeiro: Record, 2009.

VARGAS, Francisco Eduardo Beckenkamp. O mercado de trabalho e a questão do emprego no Brasil: integração precária e desenvolvimento desigual.Revista Brasileira de Sociologia / Sociedade Brasileira de Sociologia - SBS. - Vol. 02, n. 04 (jul./dez. 2014). Sergipe: SBS, 2013.

ZUKERFELD, Mariano. Bits, plataformas y autómatas. Las tendencias del trabajo en el capitalismo informacional. Revista Latinoamericana de antropología del Trabajo, num 7 (2020): 5.

\section{Recursos em meio eletrônico:}

CRELIER, Cristiane. Número de pessoas que trabalham em veículos cresce 29,2\%, maior alta da série. Agência IBGE Notícias. Estatísticas Sociais: 2019. Disponível em <https://agenciadenoticias. ibge.gov.br/agencia-noticias/2012-agencia-de-noticias/noticias/26424-numero-de-pessoas-que-trabalham-em-veiculos-cresce-29-maior-alta-da-serie>. Acessado em 25/04/2020.

EQUIPE UBER.Em quais cidades a Uber está no Brasil. Uber. Disponível em <https://www.uber. $\mathrm{com} / \mathrm{pt}$-BR/blog/em-quais-cidades-a-uber-esta-no-brasil>. Acesso em 09/04/2020.

EQUIPE UBER. Fatos e Dados sobre a Uber. Uber. Disponível em <https://www.uber.com/pt-BR/ newsroom/fatos-e-dados-sobre-uber>. Acessado em 09/04/2020.

EQUIPE UBER. Uber lança programa "Elas na Direção" para incentivar mais mulheres a gerar renda dirigindo com o app. 24/10/2019. Disponível em <https:/www.uber.com/pt-BR/newsroom/ uber-lanca-elas-na-direcao/>. Acessado em 12/10/2020.

Facebook. Disponível em<https://pt-br.facebook.com/>. Acesso em 20/10/19.

FONTES, Virgínia. In: Capitalismo em tempos de uberização: do emprego ao trabalho (06/11/2018). Disponível em <https:/www.youtube.com/watch?v=U0K-ZRXPK3k>. Acessado em 27/06/2020.

GOOGLE FORMS. Disponível em <https://www.google.com/intl/pt-BR/forms/about/>. Acesso em $04 / 01 / 2020$.

INSTITUTO BRASILEIRO DE GEOGRAFIA E ESTATÍSTICA (IBGE). Disponível em https:// www.ibge.gov.br/ . Acessado em 02/05/2020.

PNAD 2018. Desigualdades Sociais por Cor ou Raça no Brasil. IBGE. Disponível em <https:// www.ibge.gov.br/estatisticas/sociais/populacao/25844-desigualdades-sociais-por-cor-ou-raca.ht$\mathrm{ml}$ ? $=\& \mathrm{t}=$ resultados $>$. Acessado em 10/06/2020. 
REDAÇÃO. Desemprego dispara 38\% em 2015 e é o pior em 11 anos, diz IBGE. Portal UOL. Disponível em <https://economia.uol.com.br/empregos-e-carreiras/noticias/redacao/2016/11/25/ desemprego-atingiu-28-milhoes-de-pessoas-a-mais-em-2015-segundo-ibge.htm $>$.Acessado em 02/05/2020.

Registro Civil 2019. IBGE. Disponível em<https://agenciadenoticias.ibge.gov.br/agencia-sala-de-imprensa/2013-agencia-de-noticias/releases/29646-registro-civil-2019-numero-de-registros-de-casamentos-diminui-2-7-em-relacao-a-2018\#:- :text=Mas\%20os\%20casamentos\%20est\%C3\%A3o\%20durando,caiu\%20para\%2013\%2C8\%20anos>. Acessado em 22/03/2021.

SCHUELER, Paulo. O que é uma pandemia. Fiocruz. Rio de Janeiro, 2020. Disponível em <https:// www.bio.fiocruz.br/index.php/br/noticias/1763-o-que-e-uma-pandemia>. Acesso em 19/05/2021.

UBERIZAÇÃOdaVida:NaFiladoSUS(2020).15min. Direção:ElleFrancisco.Produção:Bombozilla. Disponível em <https://bombozila.com/uberizacao-da-vida-na-fila-do-sus-ep-06/?fbclid=IwAR3KEND1qOSdPB_k0w8PCdnQaQb8CLvfhGW8oVBxgRRaJ4YIVjFhEpQroCs>. Acessado em 04/06/2020.

UBER. Disponível em: <https://www.uber.com/>. Acesso em janeiro de 2020.

Fatos e dados sobre Uber. Disponível em: <https://www.uber.com/pt-BR/newsroom/fatos-e-dados-sobre-uber>. Acesso em: 11 jun. de 2020. 